\title{
Ideias de Paulo Freire aplicadas à Comunicação popular e comunitária'
}

\section{Paulo Freire's ideas applied to popular and community communication}

\section{Cicilia M. Krohling Peruzzo}

Professora do Programa de Pós-Graduação em Comunicação Social da Universidade Metodista de São Paulo. Doutora em Ciências da Comunicação pela Universidade de São Paulo (ECA-USP). Fez pós-doutorado na Universidade Nacional Autônoma do México.

<kperuzzo@uol.com.br>

\section{RESUMO}

Estudo das manifestações da comunicação popular e comunitária em práticas organizativas de movimentos populares no Brasil.Objetiva aproximar os pressupostos básicos da educação libertadora em Paulo Freire aos da comunicação popular e comunitária e discutir sobre sua presença nos movimentos populares. Objetiva ainda relacionar a práxis organizativa e de comunicação desses movimentos ao processo de construção do conhecimento. O estudo se baseia em pesquisa bibliográfica, pesquisa documental e em entrevistas em profundidade (relato de práticas) junto a lideranças comunitárias. Conclui-se que os pressupostos pedagógicos da educação libertadora ressoam nas práticas sociais e na comunicação popular com vistas à transformação da realidade e à realização dos interesses coletivos.

Palavras-chave: Comunicação comunitária. Comunicação popular. Paulo Freire.

\begin{abstract}
Study of community and popular communication in organizational practices of social movements in Brazil. It aims to carry the basic assumptions of liberating education in Paulo Freire to those of popular and community communication and discuss its presence in social movements. It also aims to relate the organizational and communication practices of these movements to the knowledge construction process. The study is based on bibliographic and documental research, and in-depth interviews in the form of life stories in conjunction with community leaders. We conclude that the pedagogical assumptions of liberating education resonate in social practices and popular communication in order to transform reality and achieve collective interests.
\end{abstract}

Keywords: Community communication. Popular communication. Paulo Freire.

\section{Introdução}

Este texto reporta a parte de uma pesquisa em realização sobre os conceitos e práticas comunicativas de organizações comunitárias e movimentos populares brasileiros, o qual pergunta sobre as origens do senso de democracia praticada nas iniciativas observadas no estudo, quais sejam o Polo Sindical da Borborema (Território da Borborema, semiárido da Paraíba); a Cooperativa

1 Versão revista e reestruturada do paper apresentado no $24^{\circ}$ Encontro Anual da Compós, Universidade Católica de Brasília, Brasília-DF, 9 a 12 de junho de 2015. 
de Produção Agropecuária União da Vitória - COPAVI, um assentamento do Movimento dos Trabalhadores Rurais Sem Terra (Paranacity - estado do Paraná); e o movimento comunitário de Heliópolis, por intermédio da União de Núcleos e Associações dos Moradores de Heliópolis e Região (UNAS), Heliópolis, capital de São Paulo.

Os objetivos são aproximar os pressupostos básicos da educação libertadora em Paulo Freire aos da comunicação popular e comunitária e discutir sobre sua presença em práticas organizativas e de comunicação de movimentos populares. Objetiva-se ainda relacionar a práxis organizativa e de comunicação desses movimentos ao processo de construção do conhecimento.

O estudo se baseia em pesquisa bibliográfica, pesquisa documental e em entrevistas em profundidade - na modalidade relato de práticas (Bertaux, 2005) - junto a lideranças comunitárias, embora não haja espaço para a documentação de falas dos entrevistados neste texto. As entrevistas foram realizadas pessoalmente durante visitas periódicas in loco. As visitas proporcionaram o conhecimento sobre processos de trabalho comunitário e as dinâmicas participativas desenvolvidas.

As ideias de Paulo Freire, educador brasileiro, marcaram toda uma época da educação brasileira, no entanto elas não ficaram restritas às salas de aula. Perpassaram a educação formal e se aninharam na educação não formal e na informal, desde a época em que mencionar explicitamente o seu nome era motivo de perseguição política e ideológica e rejeição de planos e projetos de intervenção. Setores da igreja católica alinhados à Teologia da Libertação, como o trabalho das Comunidades Eclesiais de Base (CEBs), da Pastoral da Terra (CPT), Pastoral Operária (PO), Pastoral Social (PS), entre outras; o Movimento de Educação de Base (MEB); movimentos sociais populares; organizações não governamentais (ONGs) e tantos outros atores coletivos e individuais, assumiram os pressupostos da educação dialógica e libertadora como fundamentos teóricos do trabalho, nos mais diferentes níveis e instâncias, públicos e privados.

Ao realizar a pesquisa de campo junto ao Polo Sindical da Borborema (Território da Borborema - Paraíba), a COPAVI (Paranacity-PR), e o movimento comunitário de Heliópolis - UNAS, (Heliópolis-SP), percebemos a recorrência do senso democrático como diretriz, expresso nas reuniões, discussões, tomada de decisões, na execução, iniciativas colaborativas, partilha das benesses e na contribuição de cada um para o todo. Outro aspecto recorrente é o envolvimento precedente de lideranças com CEBs e movimentos populares, o que talvez possa ser um dos elementos explicativos do atual compromisso de lideranças com as lutas sociais. 
Ao mesmo tempo em que ficam claras que essas relações têm a ver com a linha crítico-emancipadora dessas organizações, hipotetizamos - no decorrer do estudo - que a contribuição de Paulo Freire pode ter deixado ressonâncias no sentido político e pedagógico nas práticas sociais ao longo das últimas décadas, pois essa linha se vê refletida também nas práticas das CEBs e de movimentos populares. Nesse sentido, acrescentamos a hipótese de que o conhecimento advindo do modo coletivo e dialógico de atuar é a base facilitadora da conscientização sobre a própria existência e realidade local, além de abrir caminhos para a construção de processos organizativos, comunicativos, comunitários e a criação de sistemas de informação.

O ponto de partida das ideias de Paulo Freire é a situação brasileira caracterizada pela injustiça social e a necessidade de transformação. A principal parte de sua obra se refere ao contexto vivido no país nas décadas 1960 a 1980, um contexto marcado pela opressão política vigente no regime militar (1964-1985), analfabetismo acentuado, extrema pobreza e desigualdade social crescente, além da condição de manipulação político-ideológica da população.

Neste contexto ele se mostrou preocupado com a democratização da sociedade (geral) e dentro dela com a democratização da cultura, e indicou caminhos para a realização desse pleito. Claro que sua obra não se resume a esses aspectos, haja vista toda contribuição quanto ao método de alfabetização e as reflexões sobre as relações entre educadores, educandos e o mundo etc. Seu método de alfabetização de adultos, inclusive, não se restringe a ensinar a ler a escrever, mas a ler o mundo para transformar a sociedade injusta e opressora. A seguir, enfatizamos alguns aspectos dos postulados de Paulo Freire, os mais aderentes a práxis da comunicação popular e comunitária quando esta faz jus às suas origens e conceitos seminais. Trata-se de uma primeira aproximação ao tema, ainda incompleta e não conclusiva.

\section{Pressupostos freireanos aderentes a práxis da comunicação libertadora}

- Democratização da cultura

Para Paulo Freire, democratização da cultura não quer dizer vulgarização ou a popularização dos bens culturais, nem a doação ao povo do conhecimento científico que formulamos em nossos escritórios acadêmicos. Quer dizer democratização da consciência de que o povo também é produtor da cultura. Afinal "cultura é toda criação humana" (Freire, 1981, p. 109). Posicionamento que indica sua visão sobre a importância de valorizar não só a arte dos famosos e o saber dos cientistas, mas também o saber e a arte do povo. 
Paulo Freire demonstra coerência entre seus pressupostos filosóficos e as práticas que realizou, incentivou ou provocou, a exemplo dos Círculos de Cultura $^{2}$ e sua dedicação à alfabetização de adultos. Ou seja, procurou combater o analfabetismo da população que estava fora da escola. Fala da escrita e da leitura como a "chave com que o analfabeto inicia a sua introdução no mundo da comunicação escrita. O homem [a pessoa], afinal, no mundo e com o mundo. Seu papel de sujeito e não de mero e permanente objeto" (Freire, 1981, p. 109).

Portanto, não bastam palavras bonitas sobre políticas públicas de comunicação, sobre democracia, sobre participação. Se elas não forem incorporadas às práticas sociais e às políticas de governo, acabam se tornando vulgata.

\section{- Consciência crítica}

Paulo Freire acredita que a educação pode ajudar a formação da consciência crítica, de modo que as pessoas possam se tornar protagonistas da cultura e da história. Contudo, para que a capacidade de intervir na sociedade se concretize, ele propõe uma formação ampla: um processo educativo que ultrapasse o ler e o escrever palavras, uma educação que possibilite também a leitura do mundo. Para ele, o processo que envolve

[...] uma compreensão crítica do ato de ler, que não se esgota na descodificação pura da palavra escrita ou na linguagem escrita, mas que se antecipa e se alonga na 'inteligência do mundo'. A leitura do mundo precede a leitura da palavra [...]. Linguagem e realidade se prendem dinamicamente. A compreensão do texto a ser alcançada por sua leitura crítica implica a percepção das relações entre o texto e o contexto (Freire, 1982, p. 11-12).

Desse modo, no seu entender, um caminho para a democratização da sociedade e da cultura é uma educação que gere a compreensão crítica da realidade. Uma educação vinculada à vida. Tudo isso porque o sentido pedagógico de sua proposta está em possibilitar a realização do ato do conhecimento como descoberta da própria pessoa. Portanto, não como mera transferência de saber por outro. Ao discutir as relações homem-mundo, ele está justamente apontando para o conhecimento humano que se constitui

2 Assim foram chamados os núcleos de alfabetização de adultos criados por Paulo Freire. O projeto foi interrompido com a deflagração da Ditadura Militar, em 1964. Freire (1981) diz que teriam funcionado mais de 20 mil Círculos de Cultura em todo país, se não fosse a deposição do governo João Goulart. 
nessa relação. É enfático ao dizer: "O conhecimento não se estende do que julga sabedor até aqueles que se julga não saberem; o conhecimento se constitui nas relações homem-mundo, relações de transformação, e se aperfeiçoa na problematização crítica da realidade" (Freire, 1977, p. 26).

\section{- Educação das massas}

Paulo Freire alerta que a educação das "massas" pode ter a roupagem alienada e domesticadora ou ser uma força de mudança e libertação. Ele fala da importância da educação para a liberdade, para tornar o ser humano sujeito (Freire, 1981). Considera fundamental a educação das "massas" para que possam sair da condição de desinformação, manipulação e ignorância. Porque é a situação de submissão que favorece atitude de renúncia da própria capacidade de interferir e participar na transformação da sociedade. Ele está falando na Cultura do Silêncio e do mudismo instituídos na cultura brasileira desde a época colonial (1979). Em Educação, como prática da liberdade, Freire reconhece a passagem de "massa" a "povo", na fala de ex-analfabeto de Angicos, ao dizer que ele não se sentia mais massa e, sim, povo, porque havia se politizado (1981). Só a educação das "massas", na perspectiva de uma nova pedagogia, é uma força de mudança e de libertação.

O que é libertação em Paulo Freire? É libertar da condição de pensar com a cabeça das classes dominantes.

\section{- Deixar de ser sombra}

Paulo Freire registra a fala de uma senhora que participava de um curso de alfabetização em Recife: "Quero aprender a ler e a escrever para deixar de ser sombra dos outros" (Freire,1981, p. 113). Segundo Paulo Freire, essa senhora mais tarde percebeu que aprender a ler e a escrever, em si, não basta para que deixemos de ser sombra dos outros; é preciso muito mais. "Ler e escrever a palavra só nos fazem deixar de ser sombra dos outros quando, em relação dialética com a 'leitura do mundo', tem que ver com o que chamo de 're-escrita' do mundo, com sua transformação" (Freire, 2000, p. 88).

Então, educação para a liberdade é um tipo de educação capaz de fazer do ser humano sujeito da história. Razão pela qual Paulo Freire foi perseguido e exilado durante o regime militar, pois seu trabalho de alfabetização de adultos nos Círculos de Cultura vem de 1961. No entanto, seus pressupostos e ideias continuaram ecoando na práxis dos movimentos sociais populares do Brasil e mundo a fora. 
A seguir, apresentamos brevemente dois dos pressupostos da pedagogia libertadora, pois ajudam a compreender melhor a proposta de Freire.

\section{Princípios da pedagogia libertadora}

- Ser sujeito

O primeiro pressuposto: "A vocação do homem [leia-se: e da mulher] é a de ser sujeito. [...] Para ser válida, a educação deve considerar a vocação ontológica do homem - vocação de ser sujeito - e as condições em que ele vive: em tal lugar exato, em tal momento, em tal contexto" (Freire, 1979, p. 34). A realização dessa vocação se dá pela comunicação dialógica.

Paulo Freire acredita na capacidade do ser humano como realizador e protagonista. Acredita no ser humano como capaz de agir para transformar a realidade injusta e desigual. Ensina que todo processo de mudança só se efetiva se partir das condições objetivas de vida do ser humano. Diz que aprendemos uns com os outros, mesmo na relação professor-aluno.

Segundo pressuposto: a pessoa "é um ser de relações" (não de contatos). Está "no mundo e com o mundo" (Freire, 1981, p. 109). Aqui Paulo Freire está falando da responsabilidade de cada um pela feitura do mundo. A pessoa tem o dever de agir para deixar de ser manipulada, deixar de ser objeto. Deixar se manipular para Paulo Freire, significa "estar fora de si" enquanto pessoa. Significa negar a "condição humana".

Esses princípios se fazem presentes de modo visível nas práticas pedagógicas das organizações e movimentos populares enfatizados neste texto. Foram incorporados intencionalmente na práxis desses, pois, suas lideranças têm um histórico que indica passagem por CEBs, movimentos populares ou outra ação cultural ou de educação informal compromissadas com a conscientização popular e o bem comum.

- Atitude crítica

Paulo Freire, salienta a necessidade de uma permanente atitude crítica,

[...] único modo pelo qual o homem realiza sua vocação de integrarse, superando a atitude do simples ajustamento e acomodação, apreendendo temas e tarefas de sua época [...]. Uma época histórica representa uma série de aspirações, de anseios, de valores, em busca de plenificação. [...] Sua humanização ou desumanização, sua afirmação como sujeito ou sua minimização como objeto, dependem, em grande parte, de sua captação ou não desses temas (Freire, 1981, p. 44). 
Simultaneamente a situações predominantes de conformação e de submissão da população, atitudes críticas e reações sempre fizeram parte da dinâmica da sociedade brasileira, desde a época colonial ao tempo da ditadura e aos dias atuais. Estas se expressam na incorporação dos novos pressupostos na educação formal no país, na formação de quilombos, na reação ao Golpe Militar, na Campanha por Diretas Já, na eleição de um operário para presidente da República, e na constituição de milhares de organizações civis e movimentos populares motivados a estabelecer a civilidade no campo e na cidade.

É no contexto desses últimos que a nossa discussão se trava, pois, é aí que foi gestada a comunicação popular. A ação crítica de segmentos da população mexeu com a sociedade brasileira. O próprio fim do regime militar é consequência na reação da sociedade civil contra o autoritarismo político e o acirramento das contradições sociais. Muitos movimentos populares e outros atores e fatores de mudança surgiram. As ideias de Paulo Freire fervilhavam nesse ambiente. Ainda antes do esgotamento total da ditadura militar, testemunhamos muitas situações no campo da educação e dos movimentos populares em que as lideranças aplicavam princípios da educação libertadora em projetos e práticas. Paralelamente ao controle dos grandes meios de comunicação pelas forças econômicas e políticas do exercício do poder surgem manifestações de comunicação do próprio povo. Entre estas manifestações está a comunicação popular, alternativa e comunitária criada no bojo do processo de consciência-organização-ação como parte constitutiva e constituinte das práticas sociais, no nível interno e para difundir as mensagens geradas no contexto dos movimentos sociais populares, que não encontravam espaço para tanto na mídia convencional.

\section{- Comunicação como diálogo}

Do ponto de vista conceitual, Freire toma a comunicação como diálogo. Trabalha o conceito mais especificamente na obra "Extensão ou Comunicação?". Neste livro, ele se dedica à discussão das relações entre o agrônomo e o agricultor, e critica enfaticamente a adoção do "difusionismo", da difusão de inovações/ modernização, de tradição norte-americana, o que redundou na teoria da "comunicação para o desenvolvimento" ${ }^{3}$. Nesta perspectiva, a comunicação é vista como extensão da informação, como transmissão do saber, que resultam em invasão do mundo cultural do agricultor tratando-o como objeto. Ele propõe a comunicação humana como diálogo e o reconhecimento do outro como

3 Ver Peruzzo (2014). 
sujeito. Ser dialógico, diz Freire, "é não invadir. É não manipular, é não slogonizar. Ser dialógico é empenhar-se na transformação da realidade" (1977, p. 43).

A essência do seu conceito da "comunicação como diálogo" remete à reciprocidade. Em suas palavras: “Comunicar é comunicar-se em torno do significado significante. [...] Na comunicação, não há sujeitos passivos. Os sujeitos co-intencionados ao objeto de seu pensar se comunicam com seu conteúdo" (Freire, 1977, p. 67).

Venício Lima, estudioso da comunicação e cultura em Paulo Freire, identifica a perspectiva epistemológica do conceito de comunicação de Freire. Diz que ele parte da visão de natureza humana, do "homem em sua relação com o mundo enquanto Sujeito e sua relação com os outros homens em comunicação" (Lima, 2011, p. 103). E cita uma frase de Freire: "Os homens [...] não podem ser verdadeiramente humanos sem a comunicação, pois são criaturas essencialmente comunicativas. Impedir a comunicação equivale a reduzir o homem [o ser humano] à condição de coisa" (Lima, 2011). O autor também percebe de modo claro a dimensão de relação social e política da comunicação em Freire ao esclarecer sobre a relação entre o conhecer a realidade e sua transformação por sujeitos em comunicação (2011, p. 90). Percebe, ainda, que a visão de Paulo Freire da comunicação humana como diálogo supera a tradição conceitual da época sobre este conceito, ao sair da ideia de diálogo na relação Eu-Tu (Buber, 1977) - como ação interior do indivíduo - e transcender o mesmo para "ação social" direcionada para a "mudança revolucionária" (Lima, 2011, p. 102-103).

Enfim, cabe perguntar: De que forma asideias de Paulo Freire influenciaram a comunicação popular e comunitária?

\section{Princípios freireanos incorporados pela comunicação popular}

Paulo Freire, embora tenha trabalhado essencialmente no campo da educação, suas ideias contribuíram muito na formulação de conceitos e nas práticas de comunicação popular, alternativa e comunitária - ou horizontal, participativa - na América Latina. Muitos autores latino-americanos que tratam dessa comunicação, bem como da comunicação para o desenvolvimento e mudança social ${ }^{4}$ e das relações entre Educação e Comunicação, se fundamentam em concepções de Paulo Freire ou, pelo menos, partiram de suas ideias. As práticas sociais, por sua vez, ecoam em diferentes regiões e experiências, os

4 Referimo-nos à vertente da "Comunicação para o Desenvolvimento" comprometida com as mudanças a favor da população, em contraponto aos pressupostos da modernização e difusão de inovações. 
princípios do diálogo, do protagonismo popular, da participação horizontal, da criticidade e de educação emancipadora, principalmente, em se tratando da educação não formal e informal.

Os aspectos centrais da proposta pedagógica freireana é perpassada por princípios como o do diálogo (relação horizontal de comunicação); do ser humano como sujeito; da comunicação-ação para a prática da liberdade; criticidade; aderência à realidade; e comunicação para a transformação social. Como já dissemos, os conceitos da comunicação popular e comunitária e suas denominações derivadas, trazem em seu âmago alguns dos princípios da educação libertadora de Paulo Freire, os quais podem ser percebidos em estudiosos dessa vertente comunicacional, a exemplo de Mário Kaplún, Luis Ramiro Beltrán, Daniel Prieto Castillo, Juan Diaz Bordenave, Alfonso Gumucio Dagron, Rosa Maria Alfaro, Regina Festa, a própria autora e muitos outros. Também é comum que as lideranças e militantes levem adiante essas proposições colocando em prática os referidos princípios.

Agora vamos nos deter um pouco em cada um desses princípios, a luz das práticas de trabalho organizativo e comunitário dos movimentos populares e organizações congêneres, nos quais a comunicação popular e comunitária se mescla, especialmente, a partir do Polo Sindical da Borborema - Território da Borborema, semiárido da Paraíba, um assentamento dos Trabalhadores Rurais Sem Terra - Cooperativa COPAVI - em Paranacity - estado do Paraná, e o movimento comunitário de Heliópolis, por intermédio da União de Núcleos, Associações dos Moradores de Heliópolis e Região (UNAS), de Heliópolis, capital de São Paulo. Não é aconselhável separar esses princípios, pois, na prática, eles se inter-relacionam, mas, no intuito de evidenciar alguma especificidade, apontamo-nos separadamente, com a seguinte ressalva: na realidade concreta esses princípios se dão de modo integrado. Um não existe sem o outro, um ajuda a constituir o outro.

\section{- Diálogo}

O princípio do diálogo é um dos alicerces dos movimentos populares e, como tal, também é a base de atuação e da comunicação das três organizações identificadas. Todos os assuntos que envolvem as comunidades são discutidos, tudo é dialogado e combinado no coletivo. Ao fazer parte desse processo, a comunicação popular incorporou o princípio do diálogo, ao se valer da comunicação interpessoal e grupal, ao instituir a horizontalidade, ao transformar receptores em emissores-receptores e ultrapassar a ideia de que existe comunicação apenas quando ela se dá por intermédio de artefatos tecnológicos, 
ou de "meios" de comunicação. O conceito, nesta última perspectiva, não dá conta da realidade investigada nas três experiências em questão. O que há nela é, acima de tudo, uma comunicação entre pessoas do próprio lugar, uma comunicação humana dialógica, segundo a concepção de Freire, mas vai mais além ao se concretizar no relacionamento também entre estas pessoas e suas organizações representativas e congêneres, com o poder público e na sociedade. Ela se realiza basicamente pela expressão oral, a comunicação face a face, e na coordenação de ações. Mas, o diálogo com a sociedade se amplia, pois, é crescente a apropriação de tecnologias (jornal, rádio, vídeo, internet) para ressoar o alcance das vozes de segmentos subalternos do povo para falar de seus problemas, de suas demandas e conquistas, com o objetivo de repercutir informações e a concepção de mundo provindas de outras fontes - das bases da sociedade - e assim sensibilizar, promover o debate e a deixar sementes para nova hegemonia. Dessa forma, a comunicação colabora para a "construção de consensos, mas também para a constituição de espaços de diálogo na diferença" (Uranga, 2009, p. 181).

\section{- Pessoa-sujeito}

A relação da pessoa no seu ambiente de vida como sujeito (e não como objeto) é visível na COPAVI, no Polo de Borborema e no movimento comunitário de Heliópolis. Referirmo-nos ao protagonismo dos membros de uma cooperativa, dos pequenos agricultores e de moradores de uma localidade urbana na condução dos destinos de seu modo de vida e de suas atividades, na escolha das opções políticas (rejeição de sementes transgênicas), no estabelecimento de metas e na condução de suas práticas. Pois, assim é: membros das comunidades são sujeitos coletivos, pois têm a oportunidade de participar ativamente, discutir, eleger, tomar decisões, aprender, ensinar e colher os frutos das iniciativas em benefício próprio, da comunidade e do lugar.

A comunicação popular é parte integrante desse processo, segundo as modalidades que melhor se coadunam com as necessidades de cada realidade. Ás vezes basta a comunicação face a face, outras vezes, ela é acrescida de troca de experiências práticas e verbais (intercâmbio, visitas), demonstração, manifestação pública, e, em outras situações, criam-se os próprios meios (canais) de comunicação. Esses são feitos pela própria população, suas lideranças e/ou com o auxílio de aliados. Ou seja, o cidadão é protagonista desse processo de comunicação. As pessoas se tornam emissores e receptores ao mesmo tempo, como já dizia Kaplún (1985). Criam-se condições para se instituir o diálogo e o 
debate sobre temas de interesse social. É a leitura do mundo por meio da "rereleitura" da própria realidade. Abre-se o caminho para o conhecimento.

Segundo Freire (1977, p. 27), o conhecimento "reclama reflexão crítica de cada um sobre o ato mesmo de conhecer". Observamos nas experiências em questão que as relações sociais que a pessoa estabelece com os outros e com o seu entorno, como sujeito, mexem com o conhecimento dela mesma e dos que a cercam. São relações dialógicas da pessoa com o mundo. É como foi dito, permite a realização de estar com o mundo e não apenas o mundo. Ter papel ativo e não de objeto domesticado. Essas relações permitem a geração e a troca de conhecimentos, teórico e situado, pois a pessoa está em relação com outros.

Washington Uranga esclarece:

A comunicação comunitária e popular é um lugar de encontro no espaço da vida cotidiana, entre quem tem práticas diferentes. E esse lugar, como tal, é um lugar de produção de conhecimento. É um lugar de diálogo e de intercâmbio onde o conhecimento emerge. Nesse sentido, a comunicação comunitária é também uma vocação política para, desde o encontro, ser capazes de socializar o conhecimento, convertê-lo em alimento político e motor da ação no espaço público. (Uranga, 2009, p. 182).

- Comunicação-ação para a prática da liberdade

A comunicação no contexto dos movimentos populares e comunitários se ancora na prática da liberdade explicitada no exercício do direito de comunicar a partir do seu saber e da própria voz e do empoderamento das tecnologias de comunicação, as mais diversas, para colocá-las a serviço das comunidades nas lutas para mudar as condições desumanas de existência e interferir na política, nas políticas públicas e na ação do Estado. Esse direito de comunicar refere-se à recuperação do direito a ter voz, expressar-se autonomamente, sem esquecer que, em geral, o próprio resgate da voz, do poder de se manifestar e de ser ouvido, antecede e vai além de aparatos tecnológicos, mas os inclui. As tecnologias ampliam o potencial comunicativo, não resta dúvida e, ao mesmo tempo, o seu uso representa o acesso social ao patrimônio da humanidade e o exercício do direito à cidadania.

A comunicação não acontece de forma isolada, ela implica sempre em ação. A ação de agir sobre a realidade, para reconhecê-la e transformá-la. $E$, assim, também se desenvolve a consciência crítica e o conhecimento. São identificáveis as mudanças nas pessoas que atuam em movimentos sociais populares quanto ao modo de verem a realidade e o desenvolvimento pessoal. 
Portanto, essa comunicação se insere no contexto da mobilização e da ação coletiva, o que ultrapassa a noção de uso de meios (canais) de comunicação para determinados fins, ou de tomar a comunicação apenas como instrumento para conscientizar, mobilizar etc., mas chegar a seus processos. Nas práticas sociais, 0 que ocorre são processos de comunicação embutidos na dinâmica das práticas sociais, embora, por vezes, os meios se sobressaem ou se descolam delas. Por outro lado, "não há processos de comunicação que não estejam entrelaçados a estratégias de educação. Porque educação e comunicação são indissociáveis" (Uranga, 2009, p. 185).

Paulo Freire já nos indicou a perspectiva das relações entre Comunicação e Educação no livro "Extensão ou Comunicação?" (1977), embora tratasse da educação formal, especialmente da alfabetização de adultos. Atualmente, existem pela América Latina incontáveis iniciativas de trabalho social ou comunitário que se "especializaram" em promover as relações entre Educação e Comunicação no nível comunitário (às vezes também chamadas de educomunicação ou mídia educação ${ }^{5}$ ) com vistas à transformação da vida de grupos vulneráveis, junto a segmentos adolescentes e juvenis, e mesmo de adultos, que podem até nem falar mais de Paulo Freire, mas que incorporaram seus conceitos.

Portanto, não é o método de alfabetização de adultos, em si, que é apropriado pelos movimentos populares, organizações congêneres e a comunicação popular, mas alguns dos princípios embutidos no método. A proposta central nesse ambiente não é alfabetizar adultos, mas promover a informação e o crescimento intelectual da pessoa, ao contribuir para a autoemancipação de cada um por meio da ação coletiva e mobilizadora.

- Aderência à realidade/criticidade

Outro princípio apropriado de Paulo Freire é a necessidade de o trabalho educativo-comunitário ser orgânico, estar em total sintonia à realidade das pessoas envolvidas no mesmo. As palavras geradoras, como parte substancial do método de alfabetização de Freire, não eram escolhidas segundo a vontade dos educadores, mas a partir de estudo da realidade dos educandos. Se a palavra geradora era "tijolo" foi porque o ambiente em que o Círculo de Cultura acontecia era marcado pela construção civil. E, como o outro passo do método é não aprender a ler apenas palavras, mas o mundo, pressupõe o ato de propiciar

5 Apesar de algumas nuanças distintivas, em última instância, trata-se de um mesmo fenômeno. 
aos educandos a "leitura" crítica da realidade, a partir das palavras que estão aprendendo a formar e a escrever. É um ato criativo.

Até hoje em dia é perceptível a aplicação desse princípio - de partir e respeitar sempre a realidade das pessoas - nas práticas de trabalho comunitário. Particularmente, nas três experiências em questão, ele é explícito tanto nos conceitos quanto nas dinâmicas de trabalho. A preocupação com a valorização da participação ativa e do saber popular, bem como o respeito às diferenças, são princípio, meio e fim da organização comunitária do Polo da Borborema, do movimento comunitário de Heliópolis e da COPAVI, ligada ao MST.

Ao relacionar o compromisso autêntico demonstrado nas experiências em estudo, nos ordenamentos teóricos, nos sistemas operacionais e nas práticas de funcionamento dessas organizações, com as origens freireanas dos conceitos e com a história de vida de lideranças, podemos encontrar mais um elo: a passagem das lideranças por movimentos populares, CEBs ou pastorais da igreja católica, como assinalamos antes. Nessa dimensão específica, do vínculo e da aderência local como ponto de partida, há outro fator que talvez ajude a explicar o fenômeno. Nos anos 1960, a Igreja Católica adotou uma metodologia de trabalho pastoral baseada no ver-julgar-agir, mais tarde, acrescida de rever e celebrar, para despertar o senso crítico do cristão e sua capacidade de perceber a realidade em sua volta e atuar sobre ela. Ver quer dizer que o ponto de partida é observar e analisar a realidade concreta e imediata. É o conhecimento profundo da realidade, construído em conjunto por meio da comunicação humana, da troca de saberes, da ação conjugada, e com base na participação de todos do grupo. Julgar significa avaliar, entender, criticar e discernir sobre essa realidade à luz do conhecimento cristão. Agir remete a atitude de ação concreta esperada em prol do outro ou sobre a realidade julgada, de modo a contribuir para transformá-la.

A criação do método é do cardeal Joseph Cardijn, fundador do movimento Juventude Operária Católica (JOC), que sugeriu ao Vaticano a incorporação do ver-julgar-agir como parte do ensino e práticas sociais católicas, o que foi aceito pelo Papa João XXIII ao reconhecer o método na encíclica Mater et Magistra, de 1961 (O Cardeal..., [2011?]). O método se disseminou no trabalho da Igreja Católica e, especialmente no Brasil, onde teve adesão total das CEBs e do Movimento de Educação de Base (MEB), entre outros. O método tem afinidades com o pensamento de Freire que, simultaneamente, motiva o trabalho pastoral e educativo. 
- Comunicação e transformação social

A comunicação popular, alternativa e comunitária - uma vez inserida em dinâmicas mais amplas de mobilização social - contribui para fomentar um processo de educação informal que favorece a conscientização, o desenvolvimento social e a ampliação da cidadania. Portanto, voltado para a transformação da realidade, pois contribui para a desalienação humana e para um novo conhecimento. Freire (1977, p. 67), diz que"não é possível compreender o pensamento fora de sua dupla função: cognoscitiva e comunicativa".

Quanto à comunicação, para Freire, a

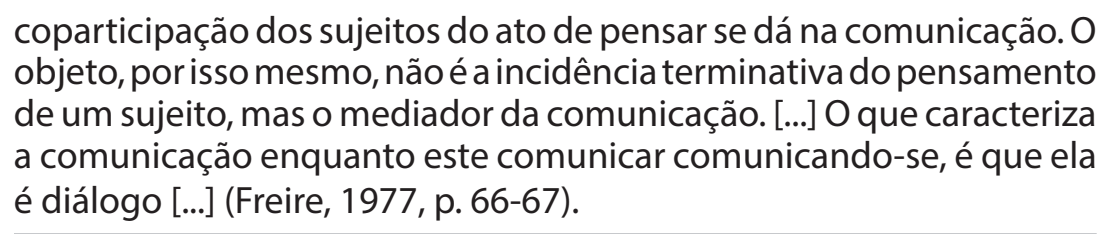

Nas três experiências analisadas, a comunicação como diálogo é parte constitutiva das mesmas. Aqui não é possível entendê-la se a tomamos apenas como meio, como instrumento, que servem para transmitir mensagens aos outros, apesar de esta ser a noção predominante nos estudos do campo da Comunicação, compreensão derivada de teorias que a entendem como um ciclo que interconecta emissor, canal e receptor. Também não é oportuno esperar uma comunicação popular e comunitária apenas mediática, que se vale de instrumentos tecnológicos, como, em geral, os estudos identificam.

Uma vez inserida nas dinâmicas cotidianas e de mobilização, como diálogo e intercâmbio de saberes, nas experiências em questão, misturamse formas de comunicação como a "coordenação de ações" (González, 2012); "comunicação como diálogo" (Freire, 1977; 1981); comunicação oral face a face; a grupal, intragrupal e a intergrupal, embora também exista aquela mediada por suportes tecnológicos, mas em menor grau (exceto quanto ao celular) e, por vezes, ausente, em conformidade com as situações de relacionamento comunicativo, necessidades e habilidades. Os suportes tecnológicos fazemse mais presentes nos relacionamentos com sociedade, no sentido amplo, segundo as necessidades e estratégias de cada situação.

Caberia perguntar: a transformação realmente ocorre? Ao se engajar no processo de comunicação, a pessoa se desenvolve e ajuda a desenvolver a comunidade. Aprende a compreender o seu entorno. Do relacionamento com o poder público municipal compreende o funcionamento do poder. Aprende a falar em público. Desenvolve a autoestima. Aprende a se relacionar em grupo. Apreende as possibilidades de manipulação da mídia. Aprende sobre o poder 
dos meios e assim por diante. Do ponto de vista coletivo, há melhoria nas condições de vida, no desenvolvimento do conhecimento e do poder popular, aspectos que se somam ao próprio desenvolvimento comunitário.

Os princípios que norteiam uma educação libertadora também contribuem para uma comunicação libertadora porque incentivam a capacidade humana de agir, criar e transformar. Mas, como alerta Freire (1979, p. 91), a ação cultural pode ter duplo sentido: "a ação cultural para a liberdade se caracteriza pelo diálogo e seu fim principal é conscientizar as massas, a ação cultural para a dominação opõe-se ao diálogo e serve para domesticá-las". Essas duas dimensões estão sempre presentes e em conflito. Daí a importância da tomada de posição em favor da transformação social que tenha no horizonte a estratégia de contribuir para o ser humano ser sujeito da história, sujeito consciente que sabe discernir as finalidades humanas das que servem aos interesses do grande capital. No fundo, o que está em questão é o tipo de desenvolvimento em vigor. Ele pode ser facilitador ou inibidor do crescimento do ser humano como sujeito. Mas, as perspectivas emancipadoras em curso provam que há possibilidade de se alterar os padrões do estar no mundo e a ajudar na transformação social.

\section{Considerações finais}

As realidades estudadas não são oásis no "deserto", perfeitas, são construções coletivas sujeitas às contradições internas e às do contexto onde se situam. Os seres humanos fazem a história, mas não a fazem como a querem, já dizia Karl Marx. Depende das condições objetivas da realidade vivida em cada época. Sendo assim, e como as condições podem ser duradouras, mas não permanentes (a história está em movimento constante), a sociedade civil se encarrega de acelerar as mudanças que vão se apresentando como necessárias.

O que acontece hoje nas experiências de Borborema, Heliópolis e Paranacity não é por vontade de poucos, mas sim como desdobramento das contradições estruturais da sociedade e de uma práxis constituída, há muitos anos, no âmbito dos movimentos populares que foram abrindo caminhos à coletivização da propriedade, do trabalho e do modo de vida (COPAVI); a descoberta do poder do pequeno produtor rural para conviver e prosperar no semiárido (Polo de Borborema); e a decisão de transformar a realidade de uma favela em uma "cidade educadora"(UNAS-Heliópolis). 


\section{Referências}

KAPLÚN, M. El comunicador popular. Quito: CIESPAL, 1985.

BUBER, M. Eu e Tu. São Paulo: Cortez, 1977.

GONZÁLEZ, J. A. Entre culturas e cibercultur@s: incursões e outras rotas não lineares. São Bernardo do Campo: Editora Metodista, 2012.

FREIRE, P. Extensão ou Comunicação? 3. ed. Rio de Janeiro: Paz e Terra, 1977.

Conscientização. Teoria e prática da libertação. São Paulo: Cortez \& Moraes, 1979.

Educação como prática da liberdade. 12. ed. Rio de Janeiro: Paz e Terra, 1981.

A importância do ato de ler. São Paulo: Cortez, 1982.

Pedagogia da autonomia. Saberes necessários à prática educativa. São Paulo: Paz e Terra, 2000.

LIMA, Venício A. de. Comunicação e cultura: as ideias de Paulo Freire. 2. ed., Brasília: UnB, 2011.

OCARDEAL que ensinou a igreja a"ver, julgar e agir". Centro de Fé e Política Dom Helder Câmara-CEFEP. Brasília: CEFEP, [2011?] Disponível em: <http://www.cefep.org. br/divulgacao/o-cardeal-que-ensinou-a-igreja-a-ver-julgar-e-agir>. Acesso em: 16 fev. 2015.

URANGA, Washington. La comunicación comunitaria: proceso cultural, social e político. In: Construyendo comunidades... Reflexiones actuales sobre comunicación comunitaria. Buenos Aires: La Crujía, p. 177-186, 2009.

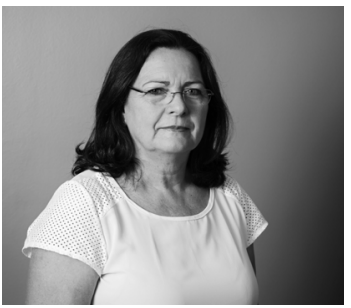

Recebido em: 3/6/2016

Aceito em: 10/6/2016

Cicilia M.Krohling Peruzzo <kperuzzo@uol.com.br>

Programa de Pós-Graduação em Comunicação Social da Universidade Metodista de São Paulo

Rua Alfeu Tavares, 149 - Rudge Ramos

09641-000 - São Bernardo do Campo - SP - Brasil 